\title{
OMCVD Grown InP/InGaAs Heterojunction Bipolar Transistors
}

\author{
H. Schumacher, J.R. Hayes, R. Bhat, and M. Koza
}

Bell Communications Research, Inc. Red Bank, NJ

InP/InGaAs heterojunction bipolar transistors (HBT's) are particularly attractive for optoelectronic integrated circuit applications due to their material compatibility with long-wavelength sources and detectors. The low surface recombination velocity ensures an excellent current gain at low collector current densities, making the device attractive for analog applications. For digital applications, suitable emitter/base compositional grading can reduce the built-in voltage to the bandgap of the base $\left(E_{\mathrm{g}}=0.78 \mathrm{eV}\right)$. Hence the emitter-base potential for a given collector current will be lower than in the AlGaAs/GaAs material system $\left(E_{g}=1.43 \mathrm{eV}\right)$, resulting in a reduced power-delay product.

Organometallic chemical vapor deposition (OMCVD) has been used to produce high-quality InP-based lasers and detectors, however no HBT's fabricated in this material system have been reported up to now. In our experiment, atmospheric pressure OMCVD was used to grow an InP/InGaAs double-heterostructure bipolar transistoron (100) sulfur doped InP substrates, using trimethylindium, trimethylgallium, arsine, and phosphine at $625 \mathrm{C}$. The base was p-doped using diethylzinc the n-layers were doped by diethyltelluride. on the $n+$ InP substrate, a 0.75 um InP collector layer $\left(n=5 \times 10^{16} \mathrm{~cm}^{-3}\right)$ was grown followed by a $150 \mathrm{~nm}$ InGaAs base $\left(p=5 \times 10^{18} \mathrm{~cm}^{-3}\right)$. On both sides of the base, a $15 \mathrm{~nm}$ doping setback was used to prevent the outdiffusion of Zn during the growth. The InP emitter layer was doped to $n=5 \times 10^{17} \mathrm{~cm}^{-3}$.

The transistors were fabricated as a two-level mesa structure with standard chemical etching techniques, using dilute $\mathrm{HCl}$ for the InP, and $4 \mathrm{H}_{2} \mathrm{SO}_{4}: \mathrm{H}_{2} \mathrm{O}_{2}: \mathrm{H}_{2} \mathrm{O}$ for the InGaAs layer. Au-Sn contacts were used for the emitter and collector, and Au-Be to the base, alloyed for $3 \mathrm{~s}$ at $380 \mathrm{C}$.

The OMCVD grown transistors showed current gains as high as 5000 at room temperature, the highest gain reported in this material system, surpassing the previous value by nearly a factor of 4 . The forward I-V characteristic of the base-emitter junction showed an ideality factor of $n=1.1$ over more than 10 decades (Fig.1). Assuming a unity injection coefficient, we obtain a minority carrier diffusion length of 7.5 um, superior to the best values obtained by either LPE or MBE. Fig.2 shows the small-signal current gain over almost three orders of magnitude of collector current, the maximum being 5000 at about $100 \mathrm{Acm}^{-2}$.

1.J.R. Hayes, F. Capasso, R.J. Malik, A.C. Gossard, and W. Wiegmann, Appl. Phys.Lett. $42(1983), 949-951$.

2.R.N. Nottenburg, H. Temkin, M.B. Panish, and R.A. Hamm, Appl.Phys.Lett. 49(1986), $1112-1114$. 


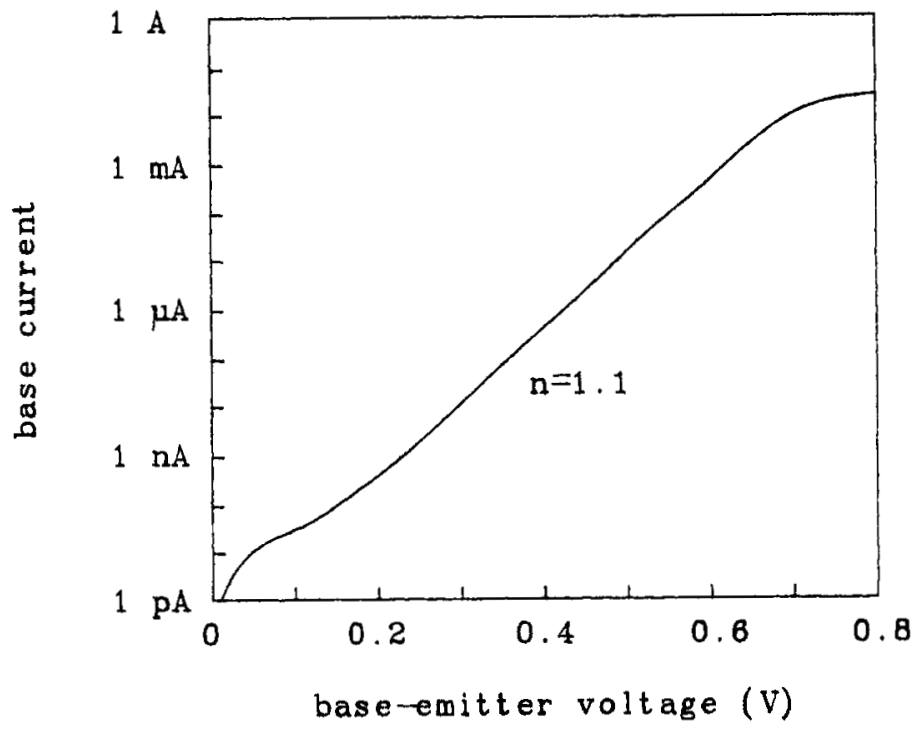

Fig. 1 Current-voltage characteristics of the forward-biased base-emitter junction, in semi-logarithmic representation

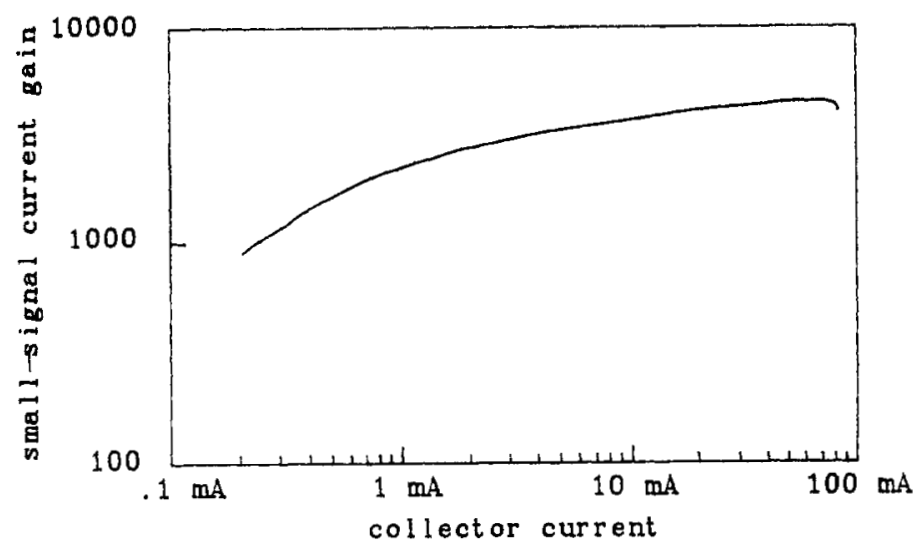

Fig.2 Small-signal current gain vs. collector current 